\title{
Reappraisal of the Importance of Rainfall in Affecting Catches of Anguilla japonica Elvers in Taiwan
}

\author{
Yuh-ling Lee Chen ${ }^{\mathrm{AD}}$, Houng-Yung Chen ${ }^{\mathrm{B}}$ and Wann-Nian Tzeng ${ }^{\mathrm{C}}$ \\ A Department of Marine Resources and ${ }^{B}$ Institute of Marine Biology, \\ National Sun Yat-sen University, Kaohsiung, Taiwan 804, Republic of China. \\ C Department of Zoology, National Taiwan University, Taipei, Taiwan 106, \\ Republic of China. \\ D To whom correspondence should be addressed.
}

\begin{abstract}
This paper relates daily mean seawater temperature and daily rainfall in northern Taiwan to the catches of $A$. japonica elvers during a two-year period. The results indicate a positive $(P<0 \cdot 05)$ relationship between rainfall and elver catches and a negative $(P<0.05)$ relationship between seawater temperature and elver catches. Peaks in elver catches generally coincided with peaks in rainfall and minimums of temperature. Rainfall is clearly as important in affecting elver catch as is seawater temperature, which was previously regarded as the key factor.
\end{abstract}

\section{Introduction}

The Japanese eel, Anguilla japonica, Temminck \& Schlegel, is a catadromous fish abundant in brackish and fresh waters along the coast of north-eastern Asian countries, including China, Japan, Korea and Taiwan. Its transparent larvae (hereafter referred to as elvers) are approximately six months old (Tzeng and Tsai 1992) when they swim into estuaries, then migrate into fresh water. During this migration, elvers are caught and are stocked in freshwater ponds. The eel is important in aquaculture in these countries.

Elvers reach the coastal and estuarine areas of Taiwan in winter between November and March. To harvest them, dip-nets are used in inner rivers, set-nets at river mouths, and hand-held trawling-nets in coastal waters (Tzeng 1985). Annual catches of elvers fluctuate dramatically (Tzeng 1986), with the highest recorded catch being more than 200 million elvers during 1978-79 and the lowest catch being less than 15 million elvers during 1982-83. Generally speaking, annual catches have averged 50 million elvers. The annual need for eel aquaculture, in contrast, exceeds 250 million elvers. This huge gap between supply and demand has been filled by imports and has caused a wide fluctuation in the price of elvers. Factors influencing the magnitude of elver catches have thus drawn much attention.

Many environmental correlates have been reported to affect the freshwater migration of anguillid elvers. Factors such as temperature, salinity, turbidity, $\mathrm{pH}$, stream-water odour, tidal cycle and moon phase have been found to act alone or in combination in influencing the migration of elvers or glass-eels (Sloane 1984; Tzeng 1985; Sorensen and Bianchini 1986; Tosi et al. 1990).

In an attempt to examine the freshwater migration behaviour of $A$. japonica elvers so as to predict the timing of successful fishing, Tzeng (1985) conducted a field investigation along the north-eastern coast of Taiwan during the four annual elver runs (November to March) between 1980 and 1984. Data on daily commercial elver catches from the estuary of the Shuang-Hsi River and neighbouring coastal waters (see Fig. 1) were compared with water temperature, tidal cycle and moon phase without the aid of statistical analysis. 
Tzeng concluded at that time that maximum catches of elvers in the coastal waters coincided with the occurrence of minimums in seawater temperature; when a temperature minimum was observed, the maximum catch often occurred on the same day or the following several days.

Recent observations have, however, prompted us to suspect that factors other than the seawater temperature minimum might be more important in affecting the elver catch. We therefore reviewed the possible causes of elver migration, using Tzeng's (1985) data. This paper examines the importance of seawater temperature and rainfall in affecting elver catches.

\section{Materials and Methods}

Records of daily rainfall were obtained from the En-Liao Observation Post of the Taiwan Weather Bureau, situated at En-Liao, not far from the mouth of the Shuang-Hsi River (Fig. 1). Seawater temperature was measured hourly by an automatic recorder operated by the Resource Survey Team of the Taiwan Power Company at En-Liao (Fig. 1). Daily mean temperatures were used in the analysis. Statistics on the daily catch of elvers were based on replies to questionnaires answered by about

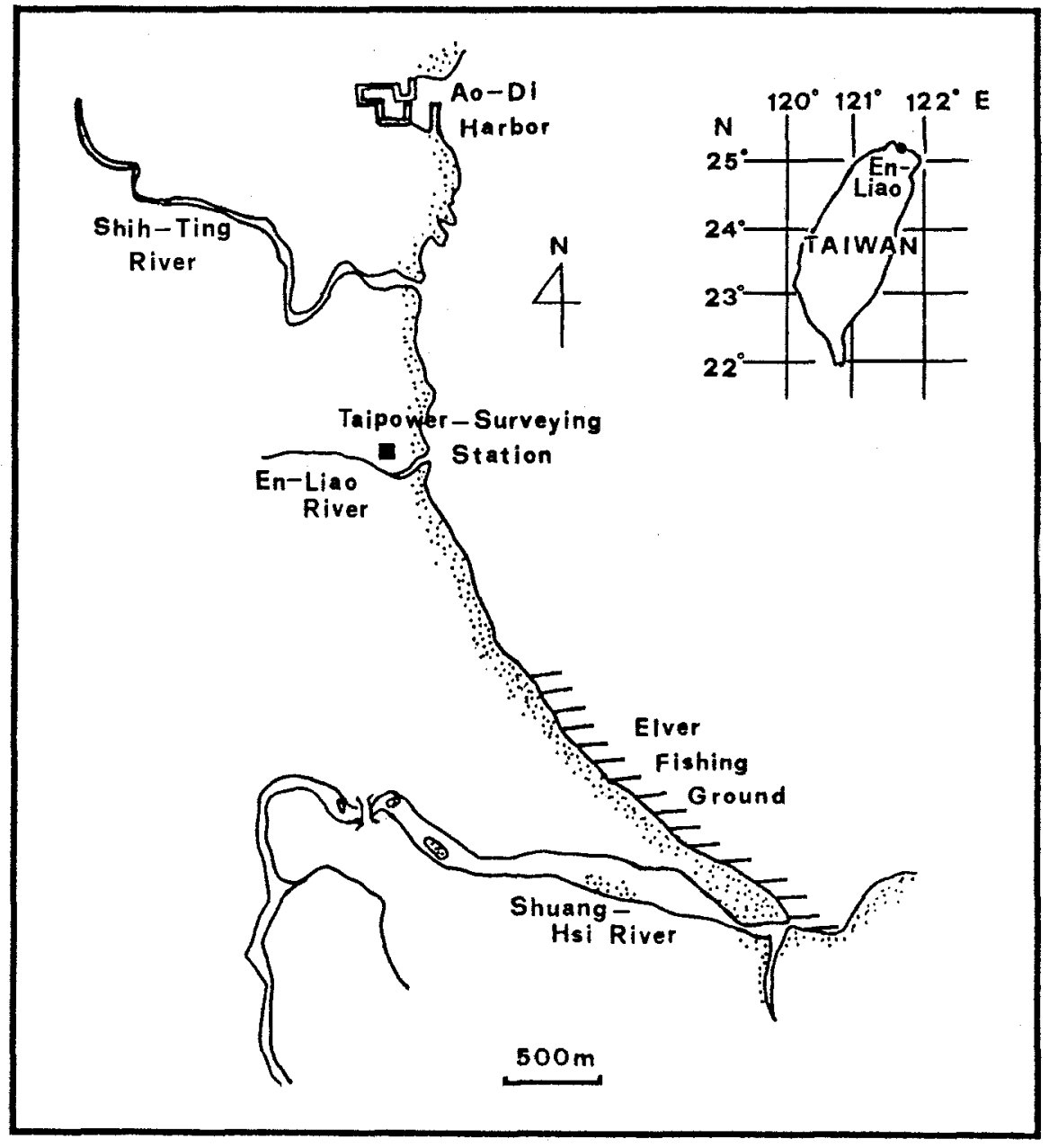

Fig. 1. Elver-fishing grounds along coastal En-Liao, northern Taiwan. 
70 fishers, who accounted for $80 \%$ of the potential fishing force in the area during the latter part of the investigation (Tzeng 1985). Fishing effort was calculated as the numbers of fishers engaged in elver harvesting. Catch was calculated as the numbers of elvers the fishers brought in. Catch per unit effort (CPUE; elvers fisher ${ }^{-1}$ day $^{-1}$ ) was calculated from fishing efforts and catches. Data obtained during the first two years (1980-81 and 1981-82) were incomplete because not many fishers participated in the investigation. Thus, only catches during the elver runs of 1982-83 and 1983-84 were studied. Regression analysis with the SAS statistical analysis system was used to elucidate how seawater temperature and daily rainfall was related to the elver catch.

\section{Results}

When the fluctuating patterns in daily mean seawater temperature and daily rainfall during the elver runs of 1982-83 (Fig. 2) and 1983-84 (Fig. 3) were compared with the patterns in daily CPUE, good fits were observed between CPUE and temperature as well as rainfall. Peaks in CPUE generally coincided with peaks in rainfall or minimums in temperature. Clearly, rainfall and low temperature attracted elvers to the fishing ground. Regression analysis indicated that both temperature and rainfall were significant factors in affecting elver catches (Table 1). During the 1982-83 elver run, temperature was a more significant factor than was rainfall. The converse was true during the 1983-84 run. The peak period in the elver run was between December and February, when seawater temperature showed a continuous falling trend. Although a slight difference between years was observed, elver catches decreased, despite major rainfall, by early or mid March when the seawater started to warm up.

\section{Discussion}

Rainfall in northern Taiwan is associated with recurrent cold periods during winter. This rainfall increases the intrusion of estuarine water to the interface with sea water and changes many environmental factors. Increases in water current, turbidity and dissolved and
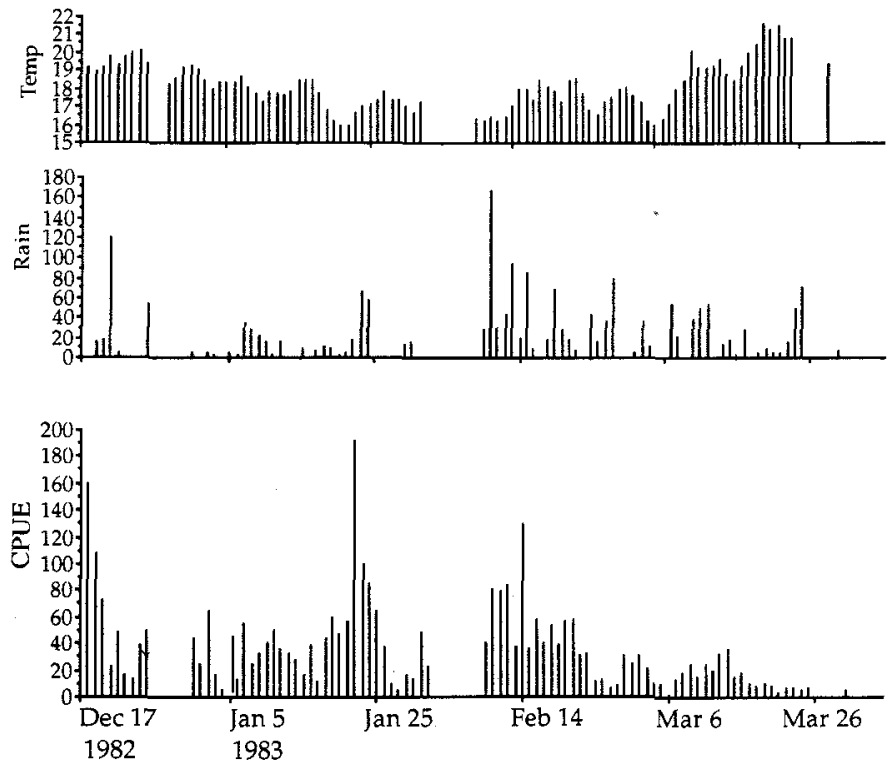

Fig. 2. Daily mean seawater temperature $\left({ }^{\circ} \mathrm{C}\right)$, daily rainfall $(\mathrm{mm})$ and catch per unit effort (CPUE, elvers fisher ${ }^{-1}$ day $^{-1}$ ) of Anguilla japonica elvers during the 1982-83 elver run. 

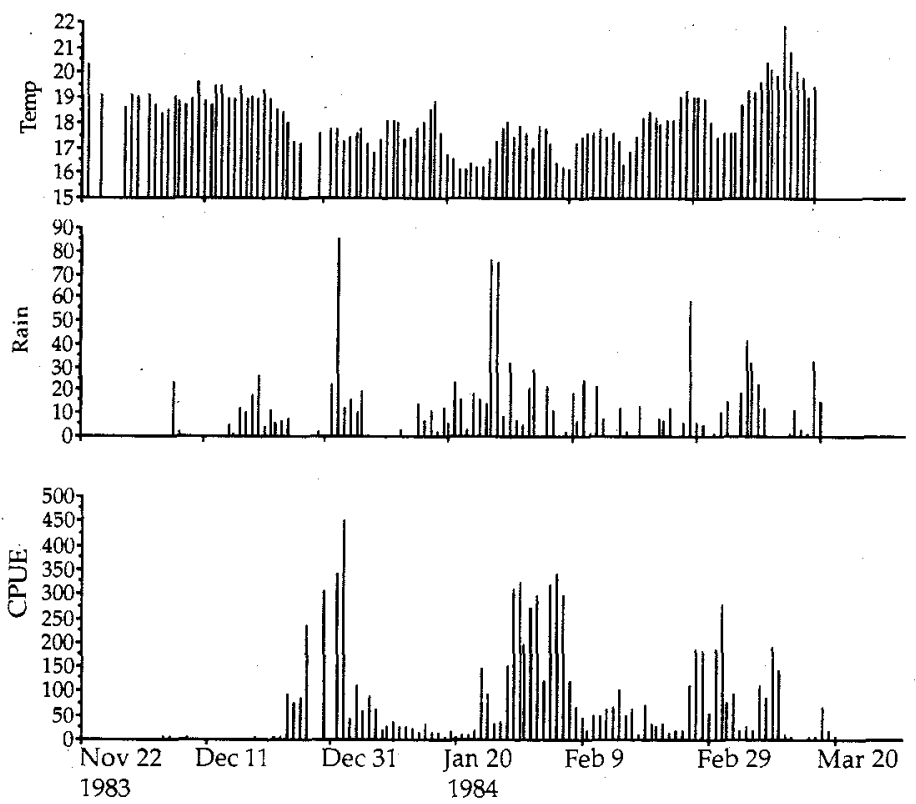

Fig. 3. Daily mean seawater temperature $\left({ }^{\circ} \mathrm{C}\right)$, daily rainfall $(\mathrm{mm})$ and catch per unit effort (CPUE, elvers fisher ${ }^{-1} \mathrm{day}^{-1}$ ) of Anguilla japonica elvers during the 1983-84 elver run.

Table 1. Results of regression analysis, showing the relationship between catch per unit effort of Anguilla japonica elvers $\left(C\right.$, elvers fisher $\left.{ }^{-1} \mathrm{day}^{-1}\right)$ and daily rainfall $(R, \mathrm{~mm})$ and daily mean seawater temperature $\left(T,{ }^{\circ} \mathrm{C}\right)$

\begin{tabular}{cll}
\hline Year & \multicolumn{1}{c}{ Regression } & \multicolumn{1}{c}{$P$} \\
\hline $1982-83(n=86)$ & $C=209 \cdot 37-9 \cdot 77 T$ & $0 \cdot 0001$ \\
& $C=27 \cdot 94+0 \cdot 23 R$ & $0 \cdot 05$ \\
$1983-84(n=1.12)$ & $C=423 \cdot 29-19 \cdot 42 T$ & 0.02 \\
& $C=47 \cdot 66+2 \cdot 27 R$ & $0 \cdot 0001$ \\
\hline
\end{tabular}

particulate organic matter and decreases in water salinity and temperature usually accompany rainfall in coastal waters. These and other factors act singly or in combination to affect the freshwater migration of elvers. It is unclear which of these factors plays a more important role than the others. Complication in an ecosystem usually makes almost all associated correlates stochastic. The present observations, however, indicate strongly that seawater temperature and rainfall in combination are a better criterion than seawater temperature alone in assessing possible elver catch or congregation prior to migration. In a study of long-adapted anguillid elvers in fresh water, Jellyman and Ryan (1983) found that elver migration correlated strongly with rainfall. Sorensen and Bianchini (1986), in a study of freshwater invasion by elvers, also indicated that rain occasionally influenced elver migration by altering river flow. On the other hand, Jellyman (1977) and Sloane (1984) described localities where rainfall apparently reduced migration by increasing current flow during freshwater migration.

Recruitment of eels into fresh water occurs in two phases: an initial invasion from the sea, and an upstream migration (Jellyman 1977). Elvers were believed to aggregate at the 
seawater/freshwater interface before they moved upstream (Jellyman 1979; Tzeng 1984). Factors inducing this aggregation are not clearly known. Rainfall could influence elver aggregation through its effect on environmental variables such as decreased salinity, increased odour from drainage water, and increased current. The American eel ( $A$. rostrata) shows a more positive rheotaxis to fresh water than to salt water, and the attractiveness of fresh water was suggested to be associated with dissolved and particulate organic matter (Miles 1968). Tosi et al. (1990), however, compared the effects of salinity, temperature and odour and showed that salinity is the most important factor guiding the choice of water by glass-eels of $A$. anguilla.

The elver catch per unit effort showed a high correlation with total fishing effort (data not shown). This seems to indicate that fishers are already aware that there is an association between elver abundance and some environmental variables. Another factor contributing to the increased effort was the fact that the elver fishers were generally not professionals. When a returning fisher brought back the message of a good harvest, resting and part-time fishers soon joined the fishing. The fishing effort thus increased sharply until catches declined.

The elver catch increased when seawater temperature declined and generally reached maximum levels when minimum temperatures occurred. Seawater temperature seems to be a good indicator in predicting the elver catch. Some researchers, however, have suggested that elvers are attracted toward estuaries by the warmer water discharged by rivers (Nyman 1972). In a laboratory observation, Chen and Chen (1991) demonstrated that the preferred water temperature of $A$. japonica elvers is always higher than their acclimatization temperature. Other workers, however, have considered that temperature, though important, does not represent the sole orientation factor because upstream migration also occurs when freshwater temperatures approach those of sea water (Tongiorgi et al. 1986).

Rainfall is no less important than seawater temperature in affecting the elver catch. In northern Taiwan, low temperatures and rainfall usually occur concurrently during winter. The observed effect of low temperature on the elver catch could be merely the result of the accompanying increased rainfall. In southern Taiwan, rainfall is not necessarily associated with low temperatures. A comparable study in that area would generate the data needed to evaluate the relative importance of rainfall and seawater temperature in affecting the elver catch.

\section{References}

Chen, Y.-L. L., and Chen, H.-Y. (1991). Temperature selections of Anguilla japonica (L.) elvers, and their implications for migration. Australian Journal of Marine and Freshwater Research 42, $743-50$.

Jellyman, D. J. (1977). Invasion of a New Zealand freshwater stream by glass-eels of two Anguilla spp. New Zealand Journal of Marine and Freshwater Research 11, 193-209.

Jellyman, D. J. (1979). Upstream migration of glass-eels (Anguilla spp.) in the Waikato River. New Zealand Journal of Marine and Freshwater Research 13, 13-22.

Jellyman, D. J., and Ryan, C. M. (1983). Seasonal migration of elvers (Anguillla spp.) into Lake Pounui, New Zealand, 1974-1978. New Zealand Journal of Marine and Freshwater Research 17, 1-15.

Miles, S. G. (1968). Rheotaxis of elvers of the American eel (Anguilla rostrata) in the laboratory to water from different streams in Nova Scotia. Journal of the Fisheries Research Board of Canada 25 , 1591-602.

Nyman, L. (1972). Some effects of temperature on eel (Anguilla) behavior. Institute of Freshwater Research, Drottningholm, Report 52, 91-102.

Sloane, R. D. (1984). Upstream migration by young pigmented freshwater eels (Anguilla australis australis Richardson) in Tasmania. Australian Journal of Marine and Freshwater Research 35, 61-73.

Sorensen, P. W., and Bianchini, M. L. (1986). Environmental correlates of the freshwater migration of elvers of American eel in a Rhode Island brook. Transactions of the American Fisheries Society 115. 258-68. 
Tongiorgi, P., Tosi, L., and Balsamo, M. (1986). Thermal preferences in upstream migrating glass-eels of Anguilla anguilla (L.). Journal of Fish Biology 28, 501-10.

Tosi, L., Spampanato, A., Sola, C., and Tongiorgi, P. (1990). Relation of water odour, salinity and temperature to ascent of glass-eels, Anguilla anguilla (L.): a laboratory study. Journal of Fish Biology 36, 327-40.

Tzeng, W. N. (1984). Dispersal and upstream migration of marked anguillid eel, Anguilla japonica, elvers in the estuary of the Shuang River, Taiwan. Bulletin of the Japanese Society of Fisheries and Oceanography 45, 12-20.

Tzeng, W. N. (1985). Immigration timing and activity rhythms of the eel, Anguilla japonica, elvers in the estuary of northern Taiwan, with emphasis on environmental influences. Bulletin of the Japanese Society of Fisheries and Oceanography 47/48, 11-27.

Tzeng, W. N. (1986). Resources and ecology of the Japanese eel Anguilla japonica elvers in the coastal waters of Taiwan. China Fisheries Monthly 404, 19-24. (In Chinese, with English abstract.)

Tzeng, W. N., and Tsai, Y.-C. (1992). Otolith microstructure and daily age of Anguilla japonica, Temminck \& Schlegel elvers from the estuaries of Taiwan with reference to unit stock and larval migration. Journal of Fish Biology 40, 845-57.

Manuscript received 11 December 1992; revised and accepted 29 July 1993 